In these, people with chronic diseases are brought together to support each other to better manage their conditions.

Since 2009, we have been involved in the Southampton Initiative for Health, which uses an empowering, problem-solving approach to improve the diets and physical activity levels of Southampton's most disadvantaged young women and their children. The programme has involved training the staff of the city's Sure Start Children's Centres - providers of services such as baby clinics, breastfeeding and weaning support, dentistry, parenting and cookery classes - in having conversations that encourage women to identify problems and generate solutions to change behaviour.

Although the data suggest that attending centres staffed by workers using this approach enhances women's sense of empowerment, to improve their nutritional status we need both to help women to feel more in control of their food choices and to make it easier for them to make better choices.

On a small scale, such a multilevel approach has proved effective. Trials in Canada, Australia and the United States demonstrate that the diets of small-town residents can be improved when efforts to enhance people's sense of empowerment in relation to healthy eating are pursued alongside local media campaigns to promote the benefits of eating well, together with programmes that help people to gain better access to fruits and vegetables and skills in food preparation. The challenge is to scale up such efforts to the wider public-health arena, because this means engaging political and commercial interests,

including those of powerful food companies.

We believe that the methods used by people working in public health to engage politicians and food companies need to undergo a similar transformation to those being used to engage individuals. So far,

\section{"We need to} help women to feel more in control of their food choices." public-health advocates have called for regulation and legislation as means to improve diets - an increased tax on fatty and sugary foods, for instance. Yet this is unlikely to happen because raising the tax on soft drinks, say, is not in the interests of industry, or of politicians, who are sensitive to industry pressures and to a public desire for cheap soft drinks.

Instead of wagging fingers, we need to generate consensus. Empowering consumers to call for better access to better food will put pressure on politicians to respond to voters, and on the food industry to please their customers.

More than 20 years ago, one of us (D.B.) wrote $^{10}$ in this journal that "if more was known about the processes by which the environment in early life influences adult health ... the rise in incidence of 'Western' disease [might be] minimized." Today, we have the knowledge to readily prevent chronic diseases, had we but the will to do so.

David Barker died on 27 August 2013, after writing the first draft of this Comment (see Nature 502, 304; 2013). Before his death, he was professor of clinical epidemiology at the Medical Research Council (MRC) Lifecourse Epidemiology Unit, University of Southampton, UK; professor of cardiovascular medicine at the Heart Research Center, Oregon Health and Science University in Portland; and visiting professor at the Center for the Study of Human Health, Emory University, Atlanta, Georgia. Mary Barker is senior lecturer in psychology at the MRC Lifecourse Epidemiology Unit, University of Southampton, UK. Tom Fleming is professor of developmental biology at the Centre for Biological Sciences, University of Southampton, UK. Michelle Lampl is director of the Center for the Study of Human Health and Professor of Anthropology at Emory University, Atlanta, Georgia.

e-mail:meb@mrc.soton.ac.uk

1. Chen, L., Magliano, D. J. \& Zimmet, P. Z. Nature Rev. Endocrinol. 8, 228-236 (2012).

2. Laslett, L. J. et al. J. Am. Coll. Cardiol. 60, S1-S49 (2012).

3. Barker, D. J. P. Brit. Med. Bull. 53, 96-108 (1997).

4. Barker, D. J. P., Eriksson, J. G., Forsén, T. \& Osmond, C. Int. J. Epidemiol. 31, 1235-1239 (2002).

5. Robker, R. L. et al. J. Clin. Endocrinol. Metab. 94, 1533-1540 (2009).

6. Barker, D. J. P. \& Thornburg, K. L. Placenta $\mathbf{3 4 ,}$ 841-845 (2013)

7. Barker, M. et al. Pub. Health Nutr. 11, 1229-1237 (2008).

8. Manandhar, D. S. et al. Lancet 364, 970-979 (2004).

9. Bodenheimer, T., Lorig, K., Holman, H. \& Grumbach, K. J. Am. Med. Assoc. 288, 2469 2475 (2002)

10.Barker, D. J. P. Nature 338, 371-372 (1989).

\title{
Global gender disparities in science
}

\section{Cassidy R. Sugimoto and colleagues present a bibliometric analysis confirming that gender imbalances persist in research output worldwide.}

$\mathrm{D}$ espite many good intentions and initiatives, gender inequality is still rife in science. Although there are more female than male undergraduate and graduate students in many countries ${ }^{1}$, there are relatively few female full professors, and gender inequalities in hiring ${ }^{2}$, earnings ${ }^{3}$, funding ${ }^{4}$, satisfaction ${ }^{5}$ and patenting ${ }^{6}$ persist.

One focus of previous research has been the 'productivity puzzle'. Men publish more papers, on average, than women ${ }^{7}$, although the gap differs between fields and subfields. Women publish significantly fewer papers in areas in which research is expensive ${ }^{8}$, such as high-energy physics, possibly as a result of policies and procedures relating to funding allocations ${ }^{4}$. Women are less likely to participate in collaborations that lead to publication and are much less likely to be listed as either first or last author on a paper ${ }^{7}$. There is no consensus on the reasons for these gender differences in research output and collaboration - whether it is down to bias,

\section{DNATURE.COM See Nature's special issue on women in science: nature.com/women}

childbearing and rearing ${ }^{9}$, or other variables. It has been suggested that what women lack in research output they make up for in citations, particularly in fields with 'greater career risk ${ }^{8}$ - that is, fields with long lags between doctoral education and securing a faculty position, such as ecology. But again, there is no consensus on the relative impact of women's work compared to men's.

The present state of quantitative knowledge of gender disparities in science has been shaped primarily by anecdotal reports and studies that are highly localized, 


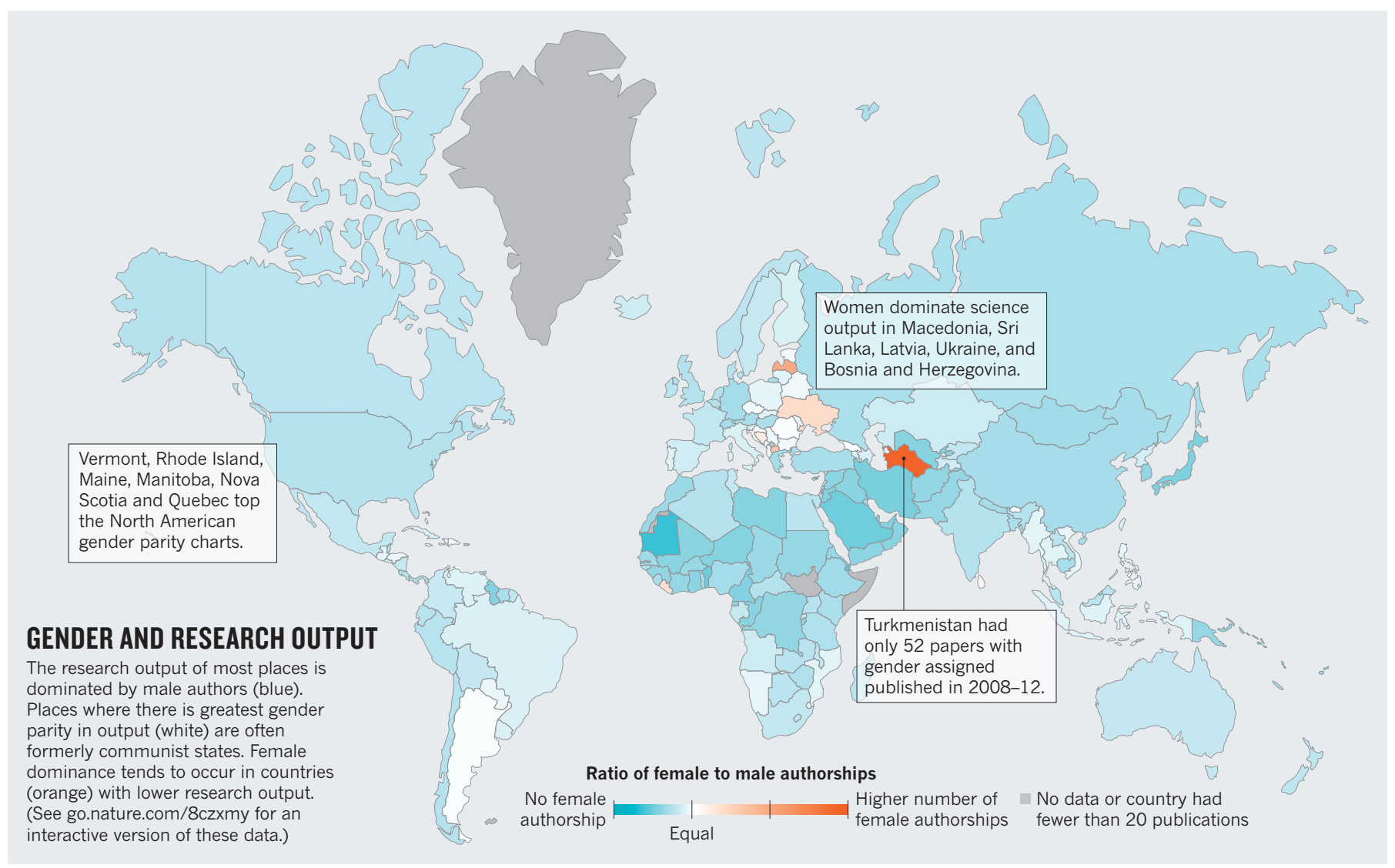

monodisciplinary and dated. Furthermore, these studies take little account of the rise in collaborative research and other changes in scholarly practices. Effective policy cannot be built on such foundations.

Therefore, we present here a global and cross-disciplinary bibliometric analysis of: first, the relationship between gender and research output (for which our proxy was authorship on published papers); second, the extent of collaboration (for which our proxy was co-authorships); and third, scientific impact of all articles published between 2008 and 2012 and indexed in the Thomson Reuters Web of Science databases (for which our proxy was citations). We analysed $5,483,841$ research papers and review articles with 27,329,915 authorships. We assigned gender using data from the US Social Security database, among other sources (see Supplementary Information; go.nature.com/j3otjz).

We find that in the most productive countries, all articles with women in dominant author positions receive fewer citations than those with men in the same positions. And this citation disadvantage is accentuated by the fact that women's publication portfolios are more domestic than their male colleagues - they profit less from the extra citations that international collaborations accrue. Given that citations now play a central part in the evaluation of researchers, this situation can only worsen gender disparities.

In our view, the scale of this study provides much-needed empirical evidence of the inequality that is still all too pervasive in science. It should serve as a call to action for the development of higher education and science policy.

\section{BIAS BY NUMBERS}

Men dominate scientific production in nearly every country; to what extent varies by region (see 'Gender and research output'). We probed the proportion of each gender's output by comparing the proportion of identified authorships for each gender on any given paper. For example, for a paper with eight authorships, of which six were assigned a gender, each of the authorships would be granted one-sixth of a paper. These gendered fractions were then aggregated at the levels of countries and disciplines. It should be stressed that these are authorships, not individuals, therefore no author name disambiguation was necessary (see Supplementary Information).

Globally, women account for fewer than $30 \%$ of fractionalized authorships, whereas men represent slightly more than $70 \%$. Women are similarly underrepresented when it comes to first authorships. For every article with a female first author, there are nearly two (1.93) articles first-authored by men.

South American and Eastern European countries demonstrate greater gender parity. Eastern Europe may support the idea that communist and formerly communist states may have greater gender balance than other countries. Only nine countries had female dominance in terms of proportion of authorships, and five of these (Macedonia, Sri Lanka, Latvia, Ukraine, and Bosnia and Herzegovina) had more than 1,000 articles in our analysis. In other words, female authorship is more prevalent in countries with lower scientific output.

Countries with more than 1,000 papers and high degrees of male dominance include, unsurprisingly (in order of output): Saudi Arabia, Iran, Japan, Jordan, the United Arab Emirates, Cameroon, Qatar and Uzbekistan. US states with more than 1,000 articles with a gender assigned and high male dominance include New Mexico, Mississippi and Wyoming. The US states and Canadian provinces that are closest to achieving gender parity (and have more than 1,000 articles) include Vermont, Rhode Island, Maine, Manitoba, Nova Scotia and Quebec. Again, some of these states and provinces are among the lowest ranking in terms of scientific output.

Our disciplinary results confirmed previous findings and anecdotal knowledge about fields associated with 'care'. Specialties dominated by women include nursing; midwifery; speech, language and hearing; education; social work and librarianship. Male-dominated disciplines include military sciences, engineering, robotics, aeronautics and astronautics, high-energy physics, mathematics, computer science, philosophy 
and economics. Although disciplines from the social sciences show a larger proportion of female authors, the humanities are still heavily dominated by men.

Next we looked at collaboration. We analysed the proportion of papers by gender that are the result of national collaboration, compared with those that result from international collaborations. For the 50 most productive countries in our analysis (accounting for $97 \%$ of the total publications), female collaborations are more domestically oriented than are the collaborations of males from the same country.

And what of impact? We analysed prominent author positions - sole authorship, first-authorship and last-authorship. We discovered that when a woman was in any of these roles, a paper attracted fewer citations than in cases in which a man was in one of these roles (see 'Lead-author gender and citation'). The gender disparity holds for national and international collaborations.

\section{AGE-OLD STORY}

There are several limitations to the conclusions that can be drawn from our findings. Foremost among them is that age indisputably has a role - perhaps even the major role - in explaining gender differences in scientific output, collaboration and impact. As is well known, the academic pipeline from junior to senior faculty leaks female scientists, and the senior ranks of science bear the imprint of previous generations' barriers to the progression of women. Thus it is likely that many of the trends we observed can be explained by the under-representation of women among the elders of science. After all, seniority, authorship position, collaboration and citation are all highly interlinked variables.

Another key limitation is that authorship of papers is only one of many indicators of research activity. Our analysis includes only journal articles, not books, conference proceedings, database construction or code, for example. Also problematic is the lack of universal norms associated with authorship attribution and posi-

tion. For example, it is possible that some women do not appear as authors despite their contribution to research activities, and there are fields in which authors are listed alphabetically. There is also a con-

"Programmes fostering international collaboration for female researchers might help to level the playing field." cern that gender-assignment techniques can introduce errors (see Supplementary Information). We have tried to mitigate this with validation exercises, but there is always room for improvement.

Future research should drill into questions raised by this analysis. What distinguishes pockets of anomalously high parity? Are there characteristics of the work itself that contribute to disparities in output and citation? Are there other, perhaps less quantitative, aspects of scholarship that reveal a different story regarding gender balance in science? Furthermore, is there anything intrinsic to certain disciplines or cultures that make them more or less appealing to scientists of a particular gender?

\section{LEVELLING THE PLAYING FIELD}

Those of a misogynistic bent might read this study as confirming their view that women's research is weaker than men's and there is less of it. Such a simplistic interpretation dismisses the vast implications embedded in these data. Our study lends solid quantitative support to what is intuitively known: barriers

\section{LEAD-AUTHOR GENDER AND CITATION}

Papers with female authors in key positions are cited less than those with male authors in key positions, be they papers with one author, or those resulting from national or international collaborations.

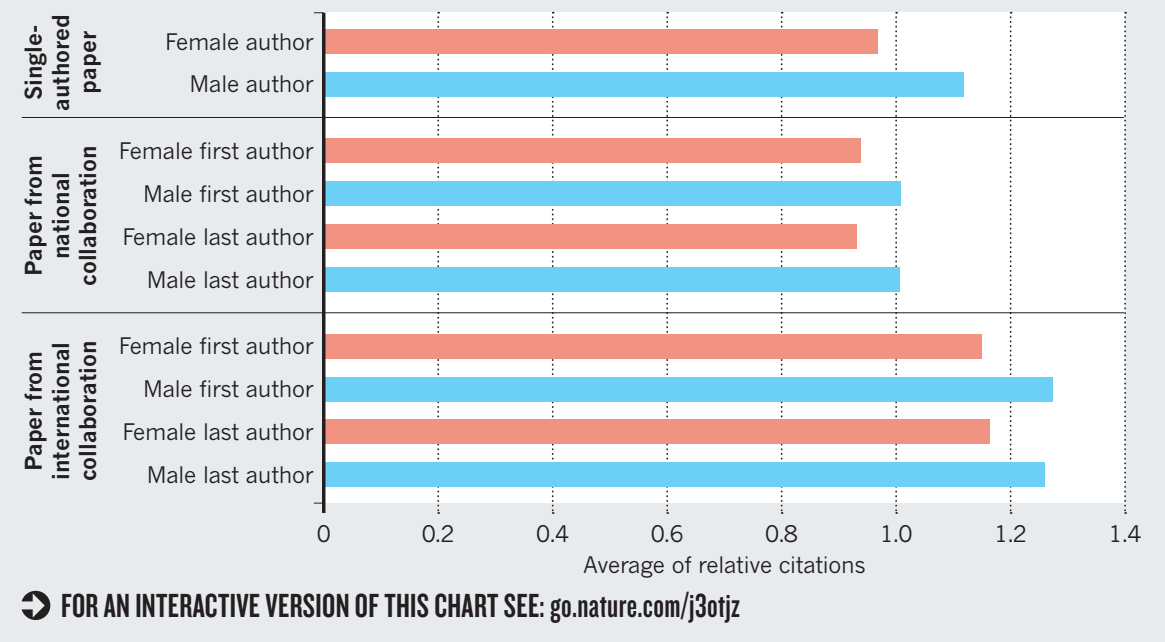

to women in science remain widespread worldwide, despite more than a decade of policies aimed at levelling the playing field. UNESCO data show ${ }^{10}$ that in $17 \%$ of countries an equal number of men and women are scientists. Yet we found a grimmer picture: fewer than $6 \%$ of countries represented in the Web of Science come close to achieving gender parity in terms of papers published.

For a country to be scientifically competitive, it needs to maximize its human intellectual capital. Our data suggest that, because collaboration is one of the main drivers of research output and scientific impact, programmes fostering international collaboration for female researchers might help to level the playing field.

That said, if there were a simple solution or programme that could improve matters, this issue would already be solved. Unfortunately, behind this global imbalance lie local and historical forces that subtly contribute to the systemic inequalities that hinder women's access to and progress in science. Any realistic policy to enhance women's participation in the scientific workforce must take into account the variety of social, cultural, economic and political contexts in which students learn science and scientific work is performed. Each country should carefully identify the micromechanisms that contribute to reproducing the past order. No country can afford to neglect the intellectual contributions of half its population.

Vincent Larivière is chaired assistant professor of transformations of scholarly communication at the University of Montreal, Canada. Chaoqun Ni is in the School of Informatics and Computing at Indiana University Bloomington. Yves Gingras is chaired professor of history and sociology of science at the University of Quebec at Montreal, Canada. Blaise Cronin is chaired professor of information science at Indiana University Bloomington. Cassidy R. Sugimoto is assistant professor in the School of Informatics and Computing, Indiana University Bloomington.

e-mail:sugimoto@indiana.edu.

1. Organisation for Economic Co-operation and Development. Education at a Glance 2012 (OECD, 2012).

2. Moss-Racusin, C. A., Dovidio, J. F., Brescoll, V. L. Graham, M. J. \& Handelsman, J. Proc. Natl Acad. Sci. USA 109, 16474-16479 (2012)

3. Shen, H. Nature 495, 22-24 (2013).

4. Ley, T. J. \& Hamilton B. H. Science $\mathbf{3 2 2}$ 1472-1474 (2008)

5. Holden, C. Science 294, 396-411 (2001).

6. Ding, W. W. Science 313, 665-667 (2006).

7. West, J. D., Jacquet, J., King, M., Correll, S. J. \& Bergstrom, C. T. PLoS ONE e66212 (2013).

8. Duch, J. et al. PLoS ONE 7, e51332 (2012).

9. Ceci, S. J. \& Williams, W. M. Proc. Natl Acad. Sci. USA 108, 3157-3162 (2011).

10.United Nations Educational, Scientific and Cultural Organization. Science, Technology and Gender: An International Report (UNESCO, 2007). 